\title{
Bride Price and the State of Marriage in North-West Ghana
}

\author{
John Boulard Forkuor ${ }^{1}$, Vincent de Paul Kanwetuu ${ }^{1}$, Eugene Muobom Ganee ${ }^{1}$, Ignatus Kpobi Ndemole ${ }^{1}$ \\ ${ }^{1}$ Department of Sociology and Social Work, Faculty of Social Sciences, Kwame Nkrumah University of Science and \\ Technology, Kumasi Ghana \\ Correspondence: John Boulard Forkuor, Department of Sociology and Social Work, Faculty of Social Sciences, Kwame \\ Nkrumah University of Science and Technology, Kumasi Ghana.
}

\author{
Received: July 13, 2018 \\ Accepted: August 7, $2018 \quad$ Available online: August 20, 2018 \\ doi:10.11114/ijsss.v6i9.3439 \\ URL: https://doi.org/10.11114/ijsss.v6i9.3439
}

\begin{abstract}
This paper sought to examine the role of bride price on the state of marriage among the Dagara of North-West Ghana. In the face of increasing scarcity of the items used in marriage in the study area, getting bride price has become a daunting task for many young men preparing to marry or already in marriage with consequences on the legitimacy and stability of families. Through purposive sampling, 5 FGDs and 9 personal interviews were conducted to obtain experiential information on bride price and state of marriage. The study revealed that the role of families, payback norms and incorporation (as part of bride price payment) are clear structures that have positive consequences for the stability of marriage; weakening potentially destabilising factors such as spousal abuse and the extra-marital sexual activities of men. Interestingly, the type and amount of items used for bride price have so much social and cultural significance that formal education and modernity has so far failed to completely change this practice among the people. The preceding allows us to conclude that the Dagara of Buo community are an epainogamous people, with societally supported marital norms and systems leading to marital stability. We recognise however that stability and longevity of marriage does not necessarily mean that spouses are 'happy and content' with their marriage. This is a relevant question that our current study did not explore. Thus, we recommend that a future quantitative study examine the relationship between marital stability and spousal 'happiness and contentment.'
\end{abstract}

Keywords: bride price, divorce, family rituals, marital stability

\section{Introduction}

The payment of bride price is practiced by many cultures around the world. For instance, in many Arab and islamic societies, bride price,termedas Mahri is an essential element in marriage rites (Muthegheki, Sausi \& Abrahams, 2012). In India, it is the bride's family that pays a dowry (money and material resources) to the grooms family (Dalama \& Lawerence, 2005). In many parts of Africa, bride price is paid in kind such as livestock or cash (Bawa, 2015). Among the Zulu and Xhosa of southern Africa for instance, the bride price ranges between a minimum of 10 cows to a maximum of 60 cows. In Ghana, the cost of bride price also varies with men in the matrilineal societies paying a smaller amount compared to men in the patrilineal societies. In northern Ghanaian societies, most of whom are patrilineal, bride price takes the form of cowries or livestock or both as custom demands. However, the exigencies of modernity has made it possible for all such items to be quantified into cash value in some societies (Dery, 2015). Among the Dagaaba, a patrilineal society of North Western Ghana, cowries and livestock are mostly used for bride price payment. However, the scarcity of cowries nowadays has compelled the Dagaaba especially those of the Nadowli and Jirapa districts to resort to the use of cash while those further North in Nandom in Ghana still insist on the cattle for payment (Korah, 2014).

In terms of cultural significance, Sarpong (1974) identifies several reasons for the payment of bride price. It ratifies the marriage, giving a certain degree of self-respect to both husband and wife. It entitles the husband to adultery fees in the event of unfaithfulness by the wife. Most important, it legitimizes children in the union. In recent times, however, bride price in some parts of Ghana especially the Nandom traditional area, has been commercialized and parents see it as an outlet from poverty. Thus, parents virtually sell off their daughters in order to amass wealth and escape poverty (Dery, 2015). This causes women to suffer subordination and consequent domestic violence leading to eventual divorce (Matembe, 2000; Oguli, 2004). For instance, Matembe (2004), Ndira (2004) and Muthegheki et al, (2012), found that the payment of bride price leads to a perception of wives as exchange commodities, which often results in spousal abuse and separation (Korah, 2014; Bawah, 2015, Dery, 2015). 
In addition to the above, the commercialization of bride price poses a challenge to young men preparing for marriage. Unlike in the days of old, not every family owns a kraal nowadays. Thus, cattle, which used to be the major economic resource of Northern Ghana, have declined over time (Awedoba, 2006) due to high cattle mortality from anthrax and rinderpest (Korah, 2014). Consequently, some young men and women tend to cohabitate while looking for money to legitimize themselves as husband and wife. This practice is, however, culturally frowned upon. If prolonged, cohabitation raises tensions between families. This paper therefore, seeks to investigate how marriages are contracted in the face of scarcity of cattle and increasing bride price. For instance, it is not clear how young men preparing for marriage are able to negotiate without the ability to provide cattle for bride price. How does this inability affect the state of marriage in terms of social relations between the bride and groom's family in contemporary times? Studies so far seem to have eluded these questions as most of them concentrate on the relationship between bride price and marital stability or divorce (Matembe, 2000;Sekaya, 2004; Oguli, 2004; Salaam, 2006) and bride price and domestic violence (Korah, 2014; Bawa, 2014; Dery, 2015).

\section{Literature Review}

Scholars have long held divergent views on the relationship between bride price and marital stability. Kressel et al. (1977) argue that bride-price is not a means of stabilizing marriage since it does not guarantee future co-operative behaviour on the part of the bride. Indeed, there are those who have claimed that it is the other way around - that it is marital stability that permits bride-price to be exacted (Gluckman 1950). The contention is that, the structure of patrilineal societies makes it possible for marriage payments to be high and this is closely linked to the stability of marriages in such societies than in matrilineal societies. The fact that in matrilineal societies the children belong unambiguously to the mother's kin group makes bride-price there comparatively low. Divorce here means that the father leaves, and since the children remain with their mother and members of her kin group divorce is here possible and common. Therefore, according to Gluckman (1950) and Mitchel (1963) the payment in patrilineal societies in essence is for the offspring, while further proof can be adduced from societies such as the Tallensi of Northern Ghana (Fortes 1949), in which parts of the bride-price are paid only upon the birth of children. The high bride price in a patrilineal society thus makes for greater stability of marriages. In direct reaction to the Gluckman Hypothesis came the work of Schneider (1953). He argues that in discussing the impact of bride price on marital stability, there is the need to distinguish between jural stability of marriage (legal bond) and conjugal stability (actual living together of husband and wife). This is especially important because the mere fact that a couple is living together does not necessarily imply a stable marriage, neither does the fact of living separately imply instability. A stable marriage should thus be viewed in both dimensions. Fallers (1957) also add that where the bride price paid signifies the incorporation of the woman into the husband's kin group, there is the greater likelihood for stability. Fallers used this to explain why some marriages are unstable even in some patrilineal societies. According to him therefore, where patriliny does not go with incorporation of the wife, it does not encourage stability. Repaying bride price on separation creates divorce restrictions, is costly and is socially stigmatizing. This draws to attention the fact that, bride price many times only ensures jural stability because of the fear of repayment upon divorce, while putting conjugal stability on the line (Sandwal, 1966; Kaye, Ekstrom \& Johansson 2005). Many research findings have also proven that, even in conjugally stable marriages, the marriage atmosphere is a tempestuous one in which the couple cannot speak of happiness, satisfaction and peaceful co-existence in the marriage. One such study is the 2002 study by Bloch and Rao in rural India. They found out that men tend to abuse their wives as a vengeance mechanism upon their feeling that the bride was overpriced. Bride price was thus seen as a factor that adversely affected the stability of marriages. Sociologists and anthropologists alike have long being interested in the impact of bride price on the stability of marriages in developing countries. Alupo (2004) cited several instances where bride price is a key factor leading to spousal abuse in marital relationships, posing great threats to the stability of marriages in Uganda. Bishai and Grossbard in their 2006 study in Uganda indicated that bride price inclines men to extra marital sexual relations and decreases such behaviours for women. The explanation is that, the payment of bride price is viewed as a payment for the woman's sexual faithfulness to the man. The logic is that, a man who buys a shirt is the only person entitled to wear that shirt but the fact that a man has bought a particular shirt does not take from him the freedom to wear other shirts. This view, however, does not hold for all societies as observed by Gray (1960) in his study of the Sonjo people.

\section{Methods}

\subsection{Area of Study}

The study was carried out in the Buo community of North-West Ghana because of its uniqueness in terms of strong patriarchal and patrilineal family systems. The community is inhabited by the Dagara people, also known as Dagaaba who extend geographically into southwest Burkina Faso (Kyoore, 2010). Even though the Dagara are double unilineal (Awedoba, 2006), patriliny is mostly practiced with married women fully incorporated into their husbands' kin groups. Among the Dagara, the payment of bride price bestows on the husband both the rights of genetricem and uxorem. Even 
though variations exist, a bride price generally comprises farm labour, first presentation of 360 cowries, second presentation of 20,000 cowries, and three cattle to be presented in two stages too.

\subsection{Data Collection}

This study used both focus groups and semi-structured interviews as the main tools for data collection. The focus groups were conducted before the semi-structured interviews. One of the researchers, fluent in the native Dagara language, moderated both the focus group discussions and conducted the semi-structured interviews while the others helped in the recording of information.

Five focus groups were conducted, with each group consisting of 5 participants. The focus groups lasted for an average of $1 \mathrm{hr}$. 30 minutes each. The discussions were conducted in the native Dagara language because most of the participants either had low levels of formal education or none at all. These discussions took place at designated social centers in the community because people gathered there to refresh and socialize as part of Christmas and other festivities during the period. Membership in each group was age and sex specific, comprising 5 males ages forty (40) and above, 5 males ages between eighteen (18) and forty (40), 5 females ages (40) and above, and 5 females ages between eighteen (18) and forty (40) and 5 unmarried young men. These gender and age distinctions were meant to enable members of each category freely share their sentiments without any form of intimidation that could have been posed by the corresponding/opposing groups. The discussions were audio recorded and later transcribed verbatim.

After the focus groups, 9 semi-structured interviews were conducted with key informants at home. While there was some form of agreement between the information emerging from the focus groups and the perception of individual respondents, it was observed that some participants, when interviewed privately, disagreed sharply with the group view.

\subsection{Data Analysis}

Data collected were analysed using the thematic approach. All recordings were translated and transcribed. The data transcript was first reorganised under the three objectives in three separate word documents. These documents were repeatedly read through in order to discover recurring codes. Similar codes were put together to form themes. These themes were used in writing the findings. The findings are presented to answer the major research questions corresponding to the objectives of study.

\subsection{Ethical Consideration}

Participants were told that their participation was voluntary. They were further briefed on how beneficial the study would be to them. We therefore solicited the oral consent of participants including the leaders of the community. They were assured maximum confidentiality and anonymity since participating in the study could have led to the revelation of some private or personal information surrounding their marriage lives and possible spousal violence.

\section{Results}

Results are presented under three main themes in line with the objectives. They include socio-cultural significance for the payment of bride price in contemporary times, the effect of bride price on the ability of young men to marry and the role of bride price on the state of marriage.

\subsection{Socio-Cultural Significance of Bride Price}

Spiritual and ancestral relevance: For most respondents, one most important reason for the payment of bride price is its spiritual connotation. In their opinion, the payments are demanded to involve the ancestors and supernatural forces as witnesses to the marriage. For instance, Dakurah, a traditional leader of the area affirmed that 'a bull is sacrificed to the ancestors so that they may also serve as witnesses to the marriage'. Similarly, Yirbome, a sectional leader emphasised that "the reason they insist on real cattle is because the bull has to be sacrificed to the gods and ancestors to invite them to acknowledge and bless the marriage." In addition to involving the ancestors as principal witnesses to the marriage through the presentation of the bull, the cowries serve as a check on the bride not to engage in extra marital sexual activities. The men under 40 corroborated the above reports by saying that unfaithfulness on the part of the woman, after the ritual is punished by the supernatural. Aleyang portrayed this in the following statement:

What happens is this, the cowries that we use to pay bride price, before they are sent to the woman's family for that purpose, they are first sent into the family shrine to draw the awareness of the gods and ancestors of the intentions of the young man to marry and help build a family. The ancestors are then invited to be witnesses of the event. When these cowries are presented to the woman's family, it means the woman is marked out for that man alone and no one else. So if the woman makes a mistake and another man sleeps with her, she can fall seriously ill and if she keeps the secret to herself, she will die. If she confesses that she has messed up, some rites can be performed to avenge the situation.

This means that bride price payment gives the groom the right of exclusive sexual access to and control over the bride. 
At death of the groom, these rights are transferable to interested younger brothers. Children born under this arrangement belong to the successor and not the deceased husband. Yirbome, a sectional leader, explaining from the perspective of the tradition said:

In case of death, any younger brother of the dead husband could bring the widow back either to keep her as wife or just for her to come and cater for the children. If the brother in question belongs to the same maternal lineage as the deceased, there would be no need for any payment again, but if he belongs to a different maternal lineage, he would have to pay 360 cowries before he can claim her as wife. In this case, the rights of the original husband are transferred to the new husband. However, it is not also compulsory that once a man dies, his brother must marry the widow.

Economic relevance: In addition to the spiritual significance, respondents also indicated that the payment of bride price has some economic relevance. It is compensation by the groom to the bride's parents for the loss of her productive labour in the family. This compensation is most evidenced in the organization of labour by the groom to the farm of the bride's father for not less than three times before the consummation of the marriage. The labourers are usually the groom's relatives, friends and all other well-wishers. Clarifying the above point, Dakurah, a community leader intimated that,

As rooted in our tradition, when you bring your woman home, the next thing to do is to organize labour to go and work on her father's farm. When you do so for about three times, you go with your parents to ask of your 'debt'. They would tell you the number of cowries, then you go later to present them. Then you continue to organize labour to her father's farm to the point that he is pleased with you.

Similarly, Ziem, in the men below 40 years category emphasised that,

Because when his daughter was still with him, she was certainly rendering very useful services to him. Now that you've married her, a void is created and must be compensated for. Otherwise, her father will call her back. However, if the groom's village is too far away, the labour can be converted to money for him to pay.

The Dagara will, therefore, maintain bride price to get economic value for their daughters.

Political and relational relevance: The payment of bride price has political implications within the marital relationship. To the respondents, bridal payment gives the groom special authority over the bride and the children. For instance, the ownership of a wife and children is solely granted by bride price paid. Analysing from the perspective of tradition, Beyuo, a community leader said:

Bride price signifies that, children born to the couple would be recruited into the kin group of the groom. The bridal payment as it is in our culture and tradition legitimizes the groom as the father of the children born out of the marriage. If he defaults in the payment of the prescribed 'goods' and services, the bride's father can claim ownership of the children and the genitor would have no authority over them. As well, the bride's father may seize the bride from the supposed husband until the culturally accepted items are paid

The perspective of the women group regarding this argument is not different. For instance, Pogpla, a woman above 40 said, 'The payment of bride price gives the groom the right to claim ownership of the children.' This means that, fatherhood of one's children is dependent on the payment of bride price.

To some respondents also, bride price gives the man or his family the authority to mourn and have the funeral rites of the wife performed in his compound in case of the death of the woman. Beyuo continued:

In our culture, the husband is the chief mourner in case his wife dies. The funeral and associated rites to be performed are done on his compound. However, if a man did not pay his wife's bride price before her death, the corpse would be carried to her natal home, and be mourned there where her father becomes the chief mourner. This then becomes a big shame and disgrace to the groom and his family.

The payment of bride price is therefore, a source of power to mourn and perform the mortuary rites of a wife and to avoid public ridicule, gossip and disgrace when one's wife dies. Dakurah reaffirmed this point with the explanation that:

The payment is done so that you don't think you are married just to joke. You know, if it is not paid, that will suggest that you are not properly married and people can just insult you in one way or the other. But when the bride price is paid, nobody can ridicule you. 


\subsection{Effect of Bride Price on Ability to Marry}

It was found that the payment of bride price does not deter young men from marrying. When asked whether a number of young men are not married because of the supposed bride price to be paid, the response was 'No! Any man of marriageable age marries, except those still in schools or learning a trade' (Segyelu). For instance, Vaartub, a participant of the unmarried young men group indicated that:

In this area, we say that the amount paid for a woman is not definitive. In other words, bride price payment is a process and not an event. Consequently, it is possible to owe. But you have to be showing concern by organizing labour on your in-laws' farm. So provided you keep doing that, you can keep your wife for five to six years, while paying the price in bits.

Dakurah, a traditional leader, further buttresses this point by saying that:

'The basic thing is the first 360 cowries.Once that is paid, the man has right to the ownership of his children. The remaining can follow in instalment'. When you've given birth to some children, you can then send two cattle followed much later by the 'nabaara' (last cow). That means you would have to have about three or four children before giving the last cow'.

From these responses, one gets the notion that the payment of bride price is a process and not merely an event. The process is also a demanding one full of negotiations in both cash and kind. There are culturally appropriate ways of circumventing an otherwise high bride price. One such way is what is referred to as 'langdinwuo'. This refers to the right to marry one's mother's brother's daughter at a reduced bride price. Aasom, a participant of the married men under 40 recounted the following:

When you see a man here in such a marital arrangement, which is what our ancestors called landingwuo. It means that the man is living with his mother's brother's daughter and based on mutual agreement, recognized by custom, decides to pay the cowries and sends one cow instead of two or more.

Apart from the 'langdinwuo', there is a system of sublime cohabitation which they do not see as cohabitation but something more or less like an "incubation" period during which time the man prepares together with the woman to "hatch" the marriage proper. 'Your living together would only be legitimized by the fact that you've initiated the customary procedures in the form of organizing labour for her father's farm. Society realizes that you are getting into marriage' (Beyuo, married man below 40). This implies that, even though the price may be high, individuals can initiate or negotiate other means of circumventing it.

\subsection{Bride Price and the State of a Marriage}

Three themes were identified under this objective: bride price and family unity, bride price and spousal abuse, bride price and incorporation.

Bride price and family unity: We found that bride price payment creates an interactive interplay between the two families, establishing friendly 'in-lawship' and fostering reciprocal rights and obligations thereby binding the families involved. This was evident in the argument of Kyaakyere, a sectional leader of the community, that, 'When you are done paying bride price, you are now a friend to your wife's father and brothers. Her mother is also your friend.' There is thus, massive involvement of both families. For instance, Pogpla, a participant of the focus group for women under forty years narrates:

Representatives of the man's family and that of the woman are both present. The number is not fixed or determinate. For me, when they came to pay my bride price, I was there in person. They had called me to ask me whether I wanted to marry the man and whether they should accept the items. They were six from my husband's family, but those from my father's home were more. I don't remember their number.

All other women confirmed the active and massive involvement of both families in the process and admitted to the fact that, such cooperation extended to times of conflicts between the couple when the two families would meet together to resolve the ensuing dispute and keep the marriage undisturbed. Both the men and women groups agreed on this. When asked whether she saw the same level of cooperation from both sides in events of misunderstanding that require their intervention, Kpere, the under 40 woman privately interviewed said: 'Yes. Representatives of both families usually come together in the same manner to solve any misunderstanding. 'This actually means that apart from uniting the families of husband and wife, the payment of the bride price also helps in resolving future marital conflicts. There is thus, a double role played by bride price.

Bride price and spousal abuse: When asked whether he would attribute abuses suffered by women in marriage to bride price, Beyuo, a sectional leader says: 
No, that is not true. Assuming you go to the market to buy a goat or a fowl, do you bring it home to beat it just because you paid a high price for it? Yet, these are animals. Why would one do the same to a woman he loves and has married? As for that assumption that women are abused because of bride price, it is a statement out of malice. It holds no truth whatsoever. There are other factors that would come in to cause such abuses. For instance, if a woman insults her husband or any member of his family, then you can say she is begging to be beaten. Or it could be that, the woman has done any other thing or refused to do something she was supposed to do. Otherwise, wife abuse as a result of bride price is unknown in our culture. Our ancestors did not know that one.

Both the old and young, individual and group categories were of the general view that other factors were the leading causes of spousal abuse. When asked whether he would beat his wife because he struggled so much to pay her bride price, this was the reply of Derbaavuor a married young man under 40 'That one doesn't hold. The fact that you've paid her bride price doesn't mean you've bought her. It is when she angers you beyond your control point that you beat her.' Even though the men (both the young and adults) unanimously disagreed with the notion that bride price leads to spousal abuse, the same could not be said of the female respondents. The women expressed ambivalent opinions on the issue. While the group of married women under 40 was generally hesitant to tell whether bride price leads to abuse of women in marriage, concluding that it depends on the kind of man one marries; their older colleagues were divided along both lines of the question. Some strongly argued in support of the view that men beat wives because they struggled to pay their bride price. Wiema explains:

But looking at it critically, is that not the case? Maybe, for some young man, he can't even buy a calf and because he had to marry he had to struggle to get cattle to pay your bride price. He will certainly use that as a basis to beat you and blame it on the least provocation.

Yuora, another married woman under age 40 revealed: 'as for beatings, he sometimes beats me'. What's worth noting from her responses was that she lived with her husband through the sublime cohabitation for a while before her bride price was paid. When asked whether her husband used to beat her during the period before her bride price was paid, this was her response; 'Not at all. Those days we didn't even have misunderstandings. It was after he paid the bride price that we started having problems. 'For her, her husband's abusive behaviour started after the payment of the bride price.

Other female respondents, however, shared a different opinion. For instance, Kusele had this to say;

Actually, it's not all men who will do that. We too, though we are all women, but we are not the same. If you come across some woman and her husband one day, you will think the woman is now the husband and the man is the wife. You see? A woman can intentionally open her mouth and insult her husband. But to open your mouth and insult your legally married husband, will you have legs to run to your father's house? That's why I say men are not the same. You can find a man who is so mild and not aggressive at all, yet the wife will be the direct opposite. I once came across a case like that, the woman was seriously raining insults on her husband as if he wasn't human at all.

One of the female respondents, who were privately interviewed, rendered some useful insight into this. When asked whether her husband has ever abused her in anyway, she answered, 'No. we do quarrel but he has never beaten me'. When asked what may cause a woman to remain in a marriage in spite of abuse, all the respondents agreed that when a woman initiates divorce, she would have to pay back the bride price to the husband. One way is for her to remarry so that her new husband would refund the former husband. If a man who takes the initiative to divorce his wife, there is no need for the woman to pay back anything to him but if it is the woman who initiates it, then there is the need for her or her family to pay the bride price back to the man. From the responses therefore, women would be disinclined to initiate divorce since they would have to payback bride price especially older women who cannot probably remarry. They may then stay in despite possible abuse. It can be seen that payback norms, therefore, partly account for marital stability.

Bride price and incorporation: There was some consensus that, once bride price is fully paid, the woman belongs to the husband's kin groups and even if the man dies, any of his younger brothers can remarry his wife without any reference to the woman's original family. The wife of Yirbome, a sectional leader adds some further insight; 'If the brother in question belongs to the same maternal lineage as the deceased, there would be no need for any payment, but if he belongs to a different maternal lineage, he would have to pay 360 cowries before he can claim her as wife. 'Interesting revelations emerged from the 2 women interviewed privately. They spoke of how they feel closely knit to their husband's families and though they said they had that sense of belonging, further probing questions revealed that Yuora, married woman under 40 had a loose sense of belonging than her older colleague. While she regularly visits her father's home like once every month, actually moves there when she felt abused among others, her older colleague, Pogpla, apart from visiting her paternal home on the yearly average of two times, she still has this to say;

When I am facing a problem I know my husband can handle, I discuss it with him. Other women can 
choose to go back to their father's home to discuss those problems with him, but for me, I've never carried my problems to my parents. When I tell my husband and he is not able to handle it, I can involve his brothers.

Incidentally, while this older woman had never at any point separated from her husband as a result of any conflict, her younger colleague separated from her husband on two occasions until the matter was resolved. This suggests that, though bride price incorporates a woman into the man's kin group, the woman still has leanings towards her natal home and the stability of the marriage still ultimately depends on the firm decision by the couple to stay together through thick and thin, not merely on account of the cultural incorporation.

\section{Discussion of Findings}

The view that bride price payment has spiritual connotation helps to stabilise marriages among the Dagara by the unseen supervision of ancestors against infidelity on the part of the woman. This corroborates the findings of Gibbs (1963) that the inclusion of elements of supernatural beliefs and practices implies that the union will be supported by supernatural sanctions as well as secular ones. This view further validates the works of Nukunya (2003), that in Africa, ancestors can influence the lives of the living. By far, the belief acts as social control of wives regarding their social, moral, psychological and spiritual lives while they remain married. The belief in ancestors as monitors of fidelity in the marriage once the bride price is paid evokes notions of Weber's theory of traditional social action. That is, individuals and families in Dagara would engage in bridal payment no matter the amount simply because they believe in the eternal yesterday; a custom instituted by their ancestors which still holds relevance today. So young men, desirous of ensuring fidelity from their wives, would go the length to pay bride price; after which their wives would go the length to remain faithful. This tradition, however, one would say, perpetuates patriarchy among the Dagara people since it borders on only the fidelity of brides to their grooms in marriage and not that of grooms to their brides. Therefore, whereas husbands can have extra-marital sex without punishment from the ancestors, wives cannot.

Subsequent to and complimenting the payment of the bride price is the organisation and execution of farm labour by the groom to the family of the bride. This is usually to compensate for the hand lost by the bride's family when she finally joins to groom in their new home. It is also meant to appreciate the bridal parents for their efforts in raising the bride into a marriageable material. Hence, scores of young men accompany the groom to labour in the farm of the bride's family. This labour by the group of accompanying young men is comparable to communal labour in the sense that every young man would eventually marry. Therefore, a young man accompanying one to work on the farms of one's in-law is creating the opportunity to be supported when it is his turn. This practice gives vitality to the concept of reciprocity, comparable to the "nnoboa and fidodo (rotational communal labour)" among the Akan and the Ewe respectively (Nukunya, 2003) in Ghana. However, whereas in the case of nnoboa and fidodo, there may be a fixed number of farmers helping each other in turns, that of the organised labour for the in-law among Dagara is open.

From the results of the study, bride price does not deter young men of the area from marrying. Every young man who reaches marriageable age marries except where he is in school or in apprenticeship training. The culture of Dagara has mechanisms that enable those who have not the economic muscle to also be able to marry. This is done through payment in stages and 'langdinwuo', i.e. the right to marry one's mother's brother's daughter (cross-cousin marriage) at a reduced cost. Though some people resort to cohabitation, it is only allowed for as transitory period to the marriage proper. Therefore, it comes with its own norms i.e. organisation of farm labour by the groom to be for the parents of the would-be bride. This is the only guarantee that permits cohabitation. Otherwise, the practice is frown upon as illegitimate. This is therefore, interpreted as appeal for more time by the groom to-be to prepare adequately for the bride price. This practice also validates Merton's theory of anomie and the innovation as a form of adaptation by those who accept the culturally approved goals but do not have the socially accepted means of achieving them. In this case, marriage is accepted as a goal by the young men but the high bride price is not attainable by all and consequently, temporal cohabitation with labour is voluntarily chosen. Since the choice of cohabitation with labour while preparing to pay the bride price is an individual's initiative, Parsons' voluntaristic theory of action is also at play in this situation. The individual selects a particular means based on rationalisation i.e. its relative ease or convenience towards goal attainment. This choice legitimizes children borne even before the payment of the bride price.

As presented earlier, bride price payment and marriage for that matter is a matter between families and not just individuals. The payment ceremonies were occasions that brought together as many witnesses as possible to observe the process. This is what Gibbs calls the ceremonialisation of the marriage bond, an avenue to call attention to the union. It emphasizes ritual symbolism of the marriage and unionisation of at least two families (Olusanya, 1970), and dramatizes essential aspects in the roles of the couples and the involvement of the two kin groups. More significantly, the event re-emphasises the fact that some sort of consensus or complementarity of expectations have been found by the couple because their relationship is important (Gibbs, 1963). This generates in both sides of the deal, a particular sense of responsibility to see 
to the preservation of the union. It is therefore not surprising that, in the event of challenges that threaten the survival of the union, both families rise to the occasion to see to the peaceful settlement of whatever dispute that could otherwise destabilize the marriage. Hence, divorce cases are rare due to the intervention of the families during times of disagreements.

In discussing the impact of bride price on marital stability, however, there is the need to distinguish between legal bonding and conjugal stability (Schneider, 1953). This is especially important because the mere fact that a couple is leaving together does not necessarily imply a stable marriage, neither does the fact of living apart imply instability. With reference to the findings of this study, a bride price, more or less, achieves jural stability than conjugal stability. This is because majority of the married participants actually admitted to some forms of abuse which led to separation but not divorce. Such separations thus disrupted conjugal stability but per jural norms, they are still regarded as husband and wife once bride price has been paid. However, the role of bride price in sustaining conjugal stability cannot be overemphasised in patrilineal Dagara society. With reference to the results again, a case in point was a catholic cardinal who gave his sister out for marriage without bride price i.e. free wife, thinking that would prevent abuse and stabilize the marriage, but it rather turned out that the woman kept reminding the man that he did not 'suffer' to marry her. Therefore, she would not be controlled. This forced the man to pay the bride price in order to own and exercise control over his wife. From this case in point, it can be induced that even women in patrilineal Dagara would only observe marriage prohibitions and reciprocal duties when their husbands 'suffer' to pay their bride price. Therefore, insofar as bride price gives recognition to a man as husband in the eyes of his wife, the practice is a unifying mechanism.

On one hand, findings from the male respondents agree that spousal abuse destabilizes marriages. However, the respondents disagree with the assertion that spousal abuse is caused by bride price payment. On the other hand, some women insisted that bride price is the reason for spousal abuse. Yet, others married women contend that factors such as disobedience, irresponsibility, disrespect, domineering and insulting attitudes by women are the causes of spousal abuse, thus corroborating responses from the majority of male respondents. These results contrast several research findings on bride price. In their 2002 study in rural India, Bloch and Rao found out that men tend to abuse their wives as a vengeance mechanism upon their feeling that the bride was overpriced. Alupo (2004) cites several instances where bride price is a key factor leading to spousal abuse in marital relationships posing great threats to the stability of marriages in Uganda. Platteau and Gaspart state the same conclusions in their 2007 study in Senegal. Compared to the Dagara of North-West Ghana, one will not be wrong in concluding that bride price is not a direct cause of marital abuse but it makes men intolerable to insubordination by their wives. This conclusion is validated by the revelation from a woman in the study who said her husband only became intolerable to her faults and misdeeds after the payment of the bride price.

There was some consensus that, once bride price is fully paid, the woman belongs to the husband's kin groups and even if the man dies, any of his younger brothers can remarry his wife without any reference to the woman's original family. This would logically make for stability as Fallers (1957) argues that where the bride price paid signifies the incorporation of the woman into the husband's kin group, there is the greater likelihood for stability. However, given the discoveries explained in our findings, cultural incorporation alone is not enough since it can remain an abstract construct without the benefit of practical reality. Hence, though bride price incorporates a woman into the man's kin group, the woman still has leanings towards her natal home and the stability of the marriage still depends on the decision by the couple to stay together and not merely on account of the cultural incorporation. Therefore, in discussing the role of incorporation as a fruit of the bride price system responsible for marital stability, there is the need to distinguish cultural incorporation from actual incorporation, though of course, the former gives impetus to the latter. Cultural incorporation in the absence of actual incorporation would be like a soul without a body; the soul wills, but the body is absent to execute the will. Fallers only talks of cultural incorporation, which though is a contributory factor, is in itself insufficient if it does not operate in consonance with its twin sister; actual incorporation.

\section{Conclusion}

The findings of this study clearly indicate the enormity of value the Dagara place on marriage in general and bride price in particular. There exist specific norms that regulate bride price payment and inter-family obligations after marriage. It has also been revealed that filiation of children and the legitimacy of the children can only be established within marriage. The implication is that children born out of wedlock are not granted full membership of the family and cannot therefore hold political office and participate in family rituals at the family shrine. Occasions for the payment of bride price have been revealed to be events that bring together relations and others to witness the union. The study also revealed that the role of families, payback norms and incorporation (as part of bride price payment) are clear structures that have positive consequences for the stability of marriage; weakening potentially destabilising factors such as spousal abuse and the extra-marital sexual activities of men. Interestingly, the type and amount of items used for bride price have so much social and cultural significance that formal education and modernity has so far failed to completely change this practice among the people. The preceding allows us to conclude that the Dagara of Buo community are an epainogamous people, with 
societally supported marital norms and systems leading to marital stability. On the basis of the results emerging from this study, we argue that bride price payment among the Dagara influences the state of a marriage by enhancing marital stability. We recognise however that stability and longevity of marriage does not necessarily mean that spouses are 'happy and content' with their marriage. This is a relevant question that our current study did not explore. Our research did not also find a strong evidence to support the argument that the payment of bride price leads to spousal abuse. It would be interesting for a future quantitative study to examine the relationship between marital stability and spousal 'happiness and contentment'.

\section{Acknowledgement}

We, the authors, wish to express our profound gratitude to the people of Buo Community in Upper West Region of Ghana, for their enthusiasm and voluntarism in participating in this study. We thank especially the study participants for their time and opinions shared during the personal interviews and the focus group discussions.

\section{Funding}

This research was co-funded by the researchers using their own income and resources without any external grants. There are no interests or conflict of interest to be disclosed.

\section{References}

Alupo, J. (2004). Bride price and gender violence. A paper presented at the International Conference on bride price and development, $16^{\text {th }}-18^{\text {th }}$ February 2004, Makerere University, Kampala, Uganda. Retrieved from: https://mifumi.org/wp-content/uploads/2017/02/MIFUMI-Bride-Price-Conference-2004_BRIDE_PRICE_AND_G ENDER_VIOLENCE_by_Josephine_Alupo.pdf

Awedoba, A. K. (2006). The people of northern Ghana. Accra, Ghana: National Commission of Culture. Retrieved on $23^{\text {rd }}$ April 2015 from www.ghanacultural.gov.gh

Bawa, J. A. (2015). Bride price n Ghana. An assesment of its social representatives in selected communities in northern Ghana. UDS International Journal of Development, 2(2), 77-87.

Bishai, D., \& Grossbard, S. (2010). Far above rubies: Bride price and extramarital sexual relations in Uganda. Journal of Population Economics, 23(4), 1177-118. https://doi.org/10.1007/s00148-008-0226-3

Bloch, F., \& Rao, V. (2002). Terror as a bargaining instrument: A case study of dowry violence in rural India. American Economic Review, 92(4), 1029-1043. https://doi.org/10.1257/00028280260344588

Dalmia, S., \& Lawrence, G. P. (2005). The institution of dowry in India: Why it continues to prevail. Journal of Developing Areas, 38(2), 71-93. https://doi.org/10.1353/jda.2005.0018

Dery, I. (2015). Bride price and domestic violence: Empirical perspectives from Nandom District in the north western region of Ghana. International Journal of Development Sustainability, 4(3), 258-271.

Fallers, L. A. (1957). Some determinants of marriage stability in Busoga: A reformulation of Gluckman's hypothesis. Journal of the International African Institute, 27(2), 106-123. https://doi.org/10.2307/1156805

Fortes, M. (1945). The dynamics of clanship among the Tallensi. London: Oxford University Press.

Gibbs, J. L. (1963). Marital instability among the Kpele: Towards a theory of Epainogamy. American Anthropologist, 65, 552-573. https://doi.org/10.1525/aa.1963.65.3.02a00040

Gluckman, M. (1950) Kinship and marriage among the Lozi of Northern Rhodesia and the Zulu of Natal in Africa. London: Oxford University Press.

Gray, F. R. (1960) Sonjo bride-price and the question of African "wife purchase". American Anthropological Association, 62(1), 34-57. https://doi.org/10.1525/aa.1960.62.1.02a00030

Kaye, D. K., Mirembe, F., Johansson, A., Ekstrom, A. M., \& Kyomuhendo, G. B. (2005). Implications of bride price on domestic violence and reproductive health in Wakiso District,Uganda. African Health Sciences, 5(4), $300-303$.

Korah, G. B. (2014). 'If it's your money, I will pay and go': shifting and contested significance of bride price payment among the Dagaaba of Northwest Ghana. Journal of Asian and African Studies, 49(3), 332-346. https://doi.org/10.1177/0021909613486088

Kressel, G., Al-Nouri, Q., Aswad, B., Divale, W., El Guindi, F., Joseph, R., Sansom, B. (1977). Bride-price reconsidered [and comments]. Current Anthropology, 18(3), 441-458. https://doi.org/10.1086/201926

Kyoore, P. K. S. (2010). A study of riddles among the Dagara of Ghana and Burkina Faso. Journal of Dagaare Studies, 7-10, 22-40. 
Matembe, M. (2004, February). The relationship between domestic violence and bride price. Paper presented at the International Bride Price Conference, Kampala, Uganda. Retrieved from https://mifumi.org/wp-content/uploads/2017/02/MIFUMI-Bride-Price-Conference-2004_Speech_by_Miria_Matem be.pdf

Mitchell, J. C. (1963). Marriage, Matriliny and Social Structure among The Yao of Southern Nyasa Land. International Journal of Comparative Sociology, 3(1), 29-42. https://doi.org/10.1177/002071526200300106

Muthegheki, S. B., Sausi, K. C., \& Abrahams, N. (2012). An exploratory study of bride price and domestic violence. South African Medical Research Council: Gender and Health Research Unit, Retrieved from http://196.21.144.194/gender/Bridepricedomesticviolence.pdf

Ndira, P. (2004, February). Bride price: A rights based view. A paper presented at the International Bride Price Conference. Kampala, Uganda.

Nukunya, G. K. (2003). Tradition and change in Ghana: An introduction to sociology. Accra: Ghana Universities Press.

Oguli, M. O. (2004). Bride Price and violence against women: the case of Uganda. Paper presented at the international conference on bride price-coalition and action to safeguard women and children in the family. Kampala, Uganda. Retrieved from https://mifumi.org/wp-content/uploads/2017/02/MIFUMI-Bride-Price-Conference 2004_BRIDE_PRICE_AND_VIOLENCE_AGAINST_WOMEN_The_case_of_Uganda_by_Margaret_Oguli_Ou mo.pdf

Olusanya, P. (1970). A note on some factors affecting the stability of marriage among the Yoruba of western Nigeria. Journal of Marriage and Family, 32(1), 150-155.

Plateau, J., \& Gaspart, F. (2007). The perverse effects of high bride prices. World Development, 35(7), 1221-1236. https://doi.org/10.1016/j.worlddev.2006.09.017

Sanwal, R. (1966). Bride wealth and marriage stability among the Khasi of Kumaon. Man, 1(1), new series, 46-59.

Sarpong, P. (1974). Ghana in retrospect: Some aspects of Ghanaian culture. Tema: Ghana Publishers Company Limited

Schneider, D. (1953). Yap kinship terminology and kin groups. American Anthropologist, 55(2), 215-236. https://doi.org/10.1525/aa.1953.55.2.02a00060

\section{Copyrights}

Copyright for this article is retained by the author(s), with first publication rights granted to the journal.

This is an open-access article distributed under the terms and conditions of the Creative Commons Attribution license which permits unrestricted use, distribution, and reproduction in any medium, provided the original work is properly cited. 